\title{
OPTIMIZING THE PROCESS PARAMETERS OF ELID GRINDING USING GREY RELATION ANALYSIS
}

\author{
Babu Aurtherson, P.*; Sundaram, S. ${ }^{* *}$; Sivapragash, M. ${ }^{* *}$ \& Shanawaz, A.M.**** \\ ${ }^{*}$ Research Scholar, Department of Manufacturing Engineering, Annamalai University, \\ Chidambaram, Tamilnadu, India \\ **Professor, Department of Manufacturing Engineering, Annamalai University, \\ Chidambaram, Tamilnadu, India

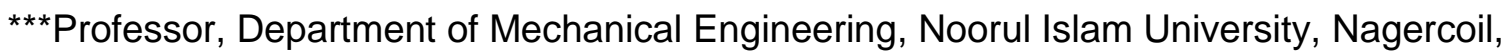 \\ Tamilnadu, India \\ ${ }^{* * * *}$ Professor, Department of Mechanical Engineering, PET Engineering College, Vallioor, \\ Tamilnadu, India \\ E-mail: pbaurtherson@gmail.com
}

\begin{abstract}
:
Composite materials have been used in considerable industrial applications due to their light weight and high strength. However, the machining costs of these materials may reach high and the grinding of these materials is much more susceptible to surface damage as compared to metals. Hence optimization of machining parameters is vital to achieve high performance in ELID grinding process. In this present work, the Design of Experiments (DOE) technique is being developed for five factors at three levels. Experiments have been conducted for measuring surface roughness, hardness, metal removal rate, normal force and tangential force based on the DOE technique in an ELID grinding machine using a cubic boron nitride wheel. A grey relation grade obtained from the grey relation analysis is used as the performance characteristic in this approach. The optimized machine parameter settings clearly improved the quality characteristics of grinding process compared to quality levels achieved for conventional machine parameter settings.
\end{abstract}

Key Words: ELID Grinding, DOE, Grey Relation Analysis, Optimization

\section{INTRODUCTION}

Metal grinding process has been one of the major manufacturing processes for centuries. In recent years, application of composite materials has increased significantly due to their light weight ratio and better mechanical properties [1]. Grinding composite materials using conventional surface grinding process shows poor surface finish and accuracy [2].

To obtain better surface finish ELID grinding technique is being adopted. A good understanding of the relationship between the work materials, cutting tool materials, cutting conditions and the process parameter is an essential requirement for the optimization of the grinding process [3-5]. ELID successfully assisted during grinding of brittle materials (BK-7 glass, and fused silica, ceramics, hard steels, ceramic coatings, etc.), having various shapes (plane, cylindrical external and internal, spherical and aspherical lenses, etc.) and dimensions [6]. More work have been carried out to determine the effect of ELID grinding in ductile mode on brittle materials that decreases the surface fracture and fragmentation and enables higher material removal rate [7].

Process optimization has also been studied extensively for various manufacturing processes including grinding [8,9]. The Grey analysis was first proposed by Dr. Deng in 1982 to fulfill the crucial mathematical criteria for dealing with poor, incomplete, and uncertain system $[10,11]$.The grey relational analysis based on the grey system theory can be used to solve complicated inter-relationships among multiple performance characteristics effectively [12]. 
This research aims at the problems related to surface finish in grinding composite materials. It is shown that the proposed method can greatly reduce the strain in the optimization procedure. Furthermore, the results of the confirmation experiments reveal that the obtained optimal combination of the grinding parameters can effectively improve surface finish and metal removal rate.

\section{ELID GRINDING MECHANISM}

The mechanism of ELID grinding for a metal bonded diamond wheel is shown in Figure 1. After truing, the grains and bonding material of the wheel surface are flattened. It is necessary for the trued wheel to be electrically pre dressed to protrude the grains on the wheel surface. When pre-dressing starts [Figure 1(a)], the bonding material flows out from the grinding wheel and an insulating layer composed of oxidized bonding material is formed on the wheel surface [Figure 1(b)]. This insulating layer reduces the electrical conductivity of the wheel surface and excessive flow-out of the bonding material from the wheel. As grinding, begins [Figure 1(c)] diamond grains wear out and the layer also becomes worn out [Figure 1(d)], as a result of which the electrical conductivity of the wheel surface increases and the electrolytic dressing starts with the flow-out of bonding material from the grinding wheel. The protrusion of diamond grains from the grinding wheel therefore remains constant. This cycle is repeated during the grinding process to achieve stable grinding.

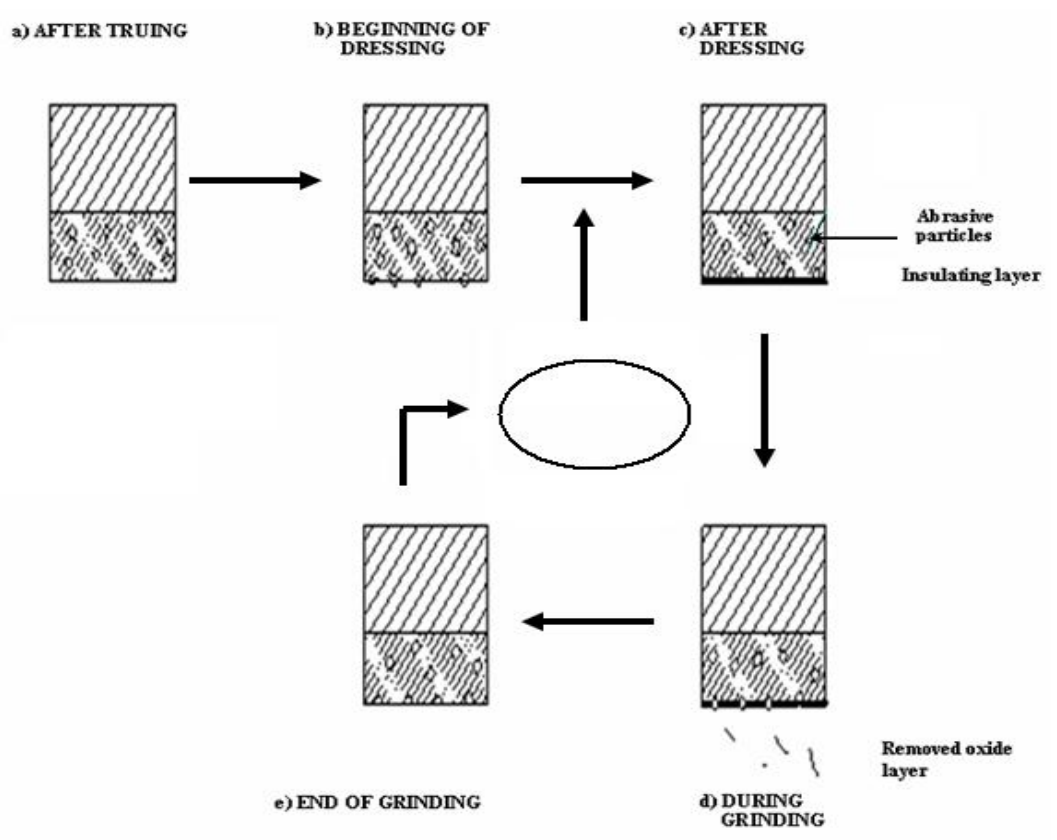

Figure 1: ELID grinding process. 


\section{EXPERIMENTAL PROCEDURE}

\subsection{ELID grinding process}

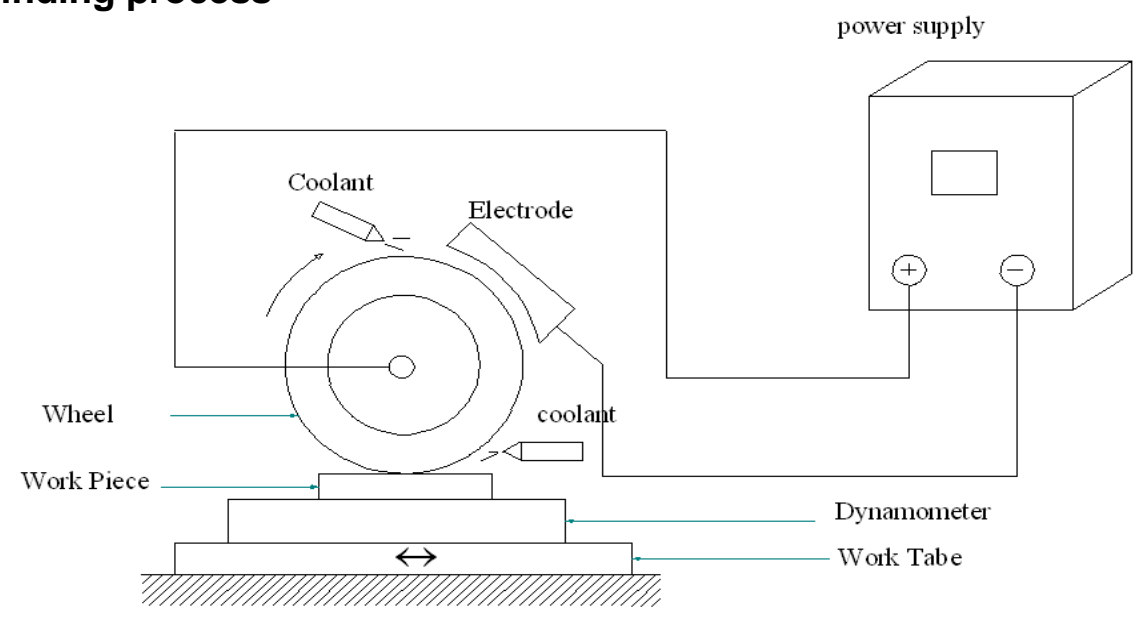

Figure 2: Schematic illustration of ELID grinding.

The experimental set is shown in Figure 2. The experiment was carried out on a precision surface grinding machine. An electrode made of copper, covering 1/6 of the perimeter of the grinding wheel, was used. The metal bonded cubic boron nitride wheel was mounted on a horizontal spindle and the gap between the grinding wheel and the copper electrode was adjusted to $0.2 \mathrm{~mm}$. The carbon brush was made in such a way to have smooth contact with the grinding wheel shaft. The dynamometer, vice and the work piece assembly were fixed on the machine table. An electric current in the form of a square pulse wave was supplied from the ELID power supply to the positive and negative poles. A standard coolant namely CG-7 was prepared with ordinary tap water in a ratio of 1:50 and used as electrolyte and coolant for the experiment. Electrolyte was applied in between the grinding wheel and the electrode to start the electrolysis.

The experiment was performed on Al-10\%SiCP composites, to study the metal removal rate, surface roughness and hardness. The normal force and tangential force were observed using a digital dynamometer. The surface roughness was measured with a Mitutoyo surftest. The micro hardness was measured using a Vickers micro hardness tester.

\subsection{Design of experiment}

In this experiment with five factors at two levels each, the fractional factorial design used is a standard L18 orthogonal array [13]. This orthogonal array is chosen due to its capability to check the interactions among factors. Each row of the matrix represents one trial. However, the sequence in which these trials are carried out is randomized. The factors and levels are assigned as in Table I. The experimental result for the machining parameters using the L18 orthogonal array is shown in Table II.

Table I: Machining parameters and their levels.

\begin{tabular}{|c|c|c|c|c|c|}
\hline SI.No & Symbols & Factors & Level I & Level II & Level III \\
\hline 1. & N & No of Pass & 50 & 100 & 150 \\
\hline 2. & W & $\begin{array}{c}\text { Work Speed } \\
(\mathrm{mm} / \mathrm{min})\end{array}$ & 200 & 300 & 400 \\
\hline 3. & D & Depth of Cut $(\mu \mathrm{m})$ & 2 & 4 & 6 \\
\hline 4. & C & $\begin{array}{c}\text { Current Duty Ratio } \\
(\%)\end{array}$ & 30 & 40 & 50 \\
\hline 5. & V & Voltage (V) & 70 & 80 & 90 \\
\hline
\end{tabular}


Babu Aurtherson, Sundaram, Sivapragash \& Shanawaz: Optimizing the Process Parameters of Elid...

Table II: Experimental results surface finish, hardness, metal removal rate, normal force and tangential force.

\begin{tabular}{|c|c|c|c|c|c|c|c|c|c|c|}
\hline $\begin{array}{c}\text { SI. } \\
\text { No }\end{array}$ & $\begin{array}{c}\text { No of } \\
\text { Pass }\end{array}$ & $\begin{array}{c}\text { Work } \\
\text { speed } \\
(\mathrm{mm} / \mathrm{min})\end{array}$ & $\begin{array}{c}\text { Depth } \\
\text { of Cut } \\
(\mu \mathrm{m})\end{array}$ & $\begin{array}{c}\text { Current } \\
\text { Duty } \\
\text { Ratio } \%\end{array}$ & $\begin{array}{c}\text { Voltage } \\
(\mathrm{V})\end{array}$ & $\begin{array}{c}\text { Roughn } \\
\text { ess } \\
(\mu \mathrm{m})\end{array}$ & $\begin{array}{c}\text { Hard } \\
\text { ness }\end{array}$ & $\begin{array}{c}\text { MRR } \\
(\mathrm{g} / \\
\mathrm{min})\end{array}$ & $\begin{array}{c}\text { Normal } \\
\text { Force } \\
(\mathrm{N})\end{array}$ & $\begin{array}{c}\text { Tangen- } \\
\text { tial Force } \\
(\mathrm{N})\end{array}$ \\
\hline 1 & 50 & 200 & 2 & 30 & 70 & 1.965 & 120.33 & 2.786 & 6.96 & 0.99 \\
\hline 2 & 50 & 200 & 4 & 40 & 80 & 1.424 & 131.62 & 2.581 & 5.78 & 0.82 \\
\hline 3 & 50 & 200 & 6 & 50 & 90 & 1.45 & 131.51 & 2.43 & 5.28 & 0.74 \\
\hline 4 & 50 & 300 & 2 & 30 & 80 & 1.98 & 120.68 & 3.62 & 4.8 & 0.78 \\
\hline 5 & 50 & 300 & 4 & 40 & 90 & 1.46 & 139.38 & 2.65 & 6.28 & 0.88 \\
\hline 6 & 50 & 300 & 6 & 50 & 70 & 1.82 & 132.68 & 2.62 & 7.12 & 1.12 \\
\hline 7 & 100 & 400 & 2 & 40 & 70 & 1.92 & 135.16 & 3.98 & 5.98 & 0.86 \\
\hline 8 & 100 & 400 & 4 & 50 & 80 & 1.78 & 128.22 & 2.79 & 6.37 & 0.84 \\
\hline 9 & 100 & 400 & 6 & 30 & 90 & 1.33 & 139.13 & 3.386 & 8.24 & 1.08 \\
\hline 10 & 100 & 200 & 2 & 50 & 90 & 1.35 & 125.53 & 2.81 & 4.98 & 0.86 \\
\hline 11 & 100 & 200 & 4 & 30 & 70 & 1.92 & 131.22 & 2.91 & 8.86 & 1.14 \\
\hline 12 & 100 & 200 & 6 & 40 & 80 & 1.62 & 138.22 & 2.92 & 9.25 & 1.21 \\
\hline 13 & 150 & 300 & 2 & 40 & 90 & 1.56 & 119.33 & 3.059 & 7.92 & 0.91 \\
\hline 14 & 150 & 300 & 4 & 50 & 70 & 1.36 & 113.67 & 2.864 & 7.29 & 0.82 \\
\hline 15 & 150 & 300 & 6 & 30 & 80 & 1.68 & 123.34 & 2.947 & 10.02 & 1.25 \\
\hline 16 & 150 & 400 & 2 & 50 & 80 & 1.37 & 131.63 & 3.232 & 7.82 & 0.79 \\
\hline 17 & 150 & 400 & 4 & 30 & 90 & 1.42 & 130.12 & 3.52 & 7.51 & 0.77 \\
\hline 18 & 150 & 400 & 6 & 40 & 70 & 1.31 & 137.18 & 3.12 & 10.8 & 1.34 \\
\hline
\end{tabular}

\section{GREY RELATION ANALYSIS}

\subsection{Grey relation}

Though the Grey relation analysis was first proposed many decades ago, it has been extensively applied only during the last decade. Grey relation analysis has been applied in evaluating the performance of a complex project with meager information. However, data to be used in Grey relation analysis must be preprocessed into quantitative indices for normalizing raw data for another analysis [14].

\subsection{Generation of Grey relation}

Under the principle of series comparability, to achieve the purpose of Grey relational analysis, we should perform data processing. This processing is called generation of Grey relation or standard processing. They are described as follows:

1. If the expected data sequence is of the form "the-higher-the-better", then the original sequence can be normalized as

$$
x_{i}^{*}(k)=\frac{x_{i}^{0}(k)-\min x_{i}^{0}(k)}{\max x_{i}^{0}(k)-\min x_{i}^{0}(k)}
$$

where $x_{i}^{0}(\mathrm{k})$ is the original sequence, $x_{i}^{*}(k)$ the sequence after the data preprocessing, max $x_{i}^{0}(\mathrm{k})$ the largest value of $x_{i}^{0}(\mathrm{k})$ and $\min x_{i}^{0}(\mathrm{k})$ implies the smallest value of $x_{i}^{0}(\mathrm{k})$. When the form "the-smaller-the-better" becomes the expected value of the data sequence, the original sequence can be normalized as 


$$
x_{i}^{*}(k)=\frac{\max x_{i}^{0}(k)-x_{i}^{0}(k)}{\max x_{i}^{0}(k)-\min x_{i}^{0}(k)}
$$

Table III: Normalized data.

\begin{tabular}{|c|c|c|c|c|c|}
\hline SI.No & $\begin{array}{c}\text { Surface } \\
\text { Roughness } \\
(\mu \mathrm{m})\end{array}$ & Hardness & $\begin{array}{c}\text { Metal Removal } \\
\text { Rate }(\mathrm{g} / \mathrm{min})\end{array}$ & $\begin{array}{l}\text { Normal } \\
\text { Force }(\mathrm{N})\end{array}$ & $\begin{array}{l}\text { Tangential } \\
\text { Force }(\mathrm{N})\end{array}$ \\
\hline 1. & 0.0224 & 0.2590 & 0.2296 & 0.6400 & 0.5833 \\
\hline 2. & 0.8299 & 0.6982 & 0.0974 & 0.8366 & 0.8666 \\
\hline 3. & 0.7910 & 0.6939 & 0.0000 & 0.9200 & 1.0000 \\
\hline 4. & 0.0000 & 0.2727 & 0.7677 & 1.0000 & 0.9333 \\
\hline 5. & 0.7761 & 1.0000 & 0.1419 & 0.7533 & 0.7666 \\
\hline 6. & 0.2388 & 0.7394 & 0.1225 & 0.6133 & 0.3666 \\
\hline 7. & 0.0896 & 0.8359 & 1.0000 & 0.8033 & 0.8000 \\
\hline 8. & 0.2985 & 0.5659 & 0.2322 & 0.7383 & 0.8333 \\
\hline 9. & 0.9701 & 0.9903 & 0.6167 & 0.4266 & 0.4333 \\
\hline 10. & 0.9403 & 0.4613 & 0.2451 & 0.9700 & 0.8000 \\
\hline 11. & 0.0896 & 0.6826 & 0.3096 & 0.3233 & 0.3333 \\
\hline 12. & 0.5373 & 0.9549 & 0.3161 & 0.2583 & 0.2166 \\
\hline 13. & 0.6269 & 0.2201 & 0.4058 & 0.4800 & 0.7166 \\
\hline 14. & 0.9254 & 0.0000 & 0.2800 & 0.5850 & 0.8666 \\
\hline 15. & 0.4478 & 0.3761 & 0.3335 & 0.1300 & 0.1500 \\
\hline 16. & 0.9104 & 0.6986 & 0.5174 & 0.4966 & 0.9166 \\
\hline 17. & 0.8358 & 0.6398 & 0.7032 & 0.5483 & 0.9500 \\
\hline 18. & 1.0000 & 0.9144 & 0.4451 & 0.0000 & 0.0000 \\
\hline
\end{tabular}

However, when the demanded value becomes the expected value in the analysis, the original sequence can be normalized as following to achieve the destination as close as possible:

$$
x_{i}^{*}(k)=1-\frac{\left|x_{i}^{0}(k)-x^{0}\right|}{\max \left(\max x_{i}^{0}(k)-x^{0} ; x^{0}-\min x_{i}^{0}(k)\right)}
$$

Where $x^{0}$ implies the destination of the assigned value in the data sequence. The normalized data of surface roughness, hardness, metal removal rate, normal force and tangential force are shown on Table III. 


\subsection{Computing the grey relational coefficient}

Table IV: Grey relational coefficient.

\begin{tabular}{|c|c|c|c|c|c|}
\hline SI. No & $\begin{array}{c}\text { Surface } \\
\text { Roughness }((\mu \mathrm{m})\end{array}$ & Hardness & $\begin{array}{c}\text { Metal Removal } \\
\text { Rate }(\mathrm{g} / \mathrm{min})\end{array}$ & $\begin{array}{c}\text { Normal } \\
\text { Force }(\mathrm{N})\end{array}$ & $\begin{array}{c}\text { Tangential } \\
\text { Force }(\mathrm{N})\end{array}$ \\
\hline 1. & 0.5057 & 0.5744 & 0.5648 & 0.7352 & 0.7058 \\
\hline 2. & 0.8546 & 0.7682 & 0.5256 & 0.8595 & 0.8823 \\
\hline 3. & 0.8272 & 0.7656 & 0.5000 & 0.9259 & 1.0000 \\
\hline 4. & 0.5000 & 0.5789 & 0.8115 & 1.0000 & 0.9375 \\
\hline 5. & 0.8171 & 1.0000 & 0.5381 & 0.8021 & 0.8108 \\
\hline 6. & 0.5678 & 0.7933 & 0.5326 & 0.7211 & 0.6122 \\
\hline 7. & 0.5234 & 0.8590 & 1.0000 & 0.8356 & 0.8333 \\
\hline 8. & 0.5877 & 0.6973 & 0.5656 & 0.7926 & 0.8571 \\
\hline 9. & 0.9710 & 0.9904 & 0.7229 & 0.6355 & 0.6382 \\
\hline 10. & 0.9437 & 0.6499 & 0.5698 & 0.9708 & 0.8333 \\
\hline 11. & 0.5234 & 0.7591 & 0.5916 & 0.5964 & 0.6000 \\
\hline 12. & 0.6837 & 0.9568 & 0.5938 & 0.5741 & 0.5607 \\
\hline 13. & 0.7283 & 0.5618 & 0.6272 & 0.6578 & 0.7792 \\
\hline 14. & 0.9306 & 0.5000 & 0.5813 & 0.7067 & 0.8823 \\
\hline 15. & 0.6442 & 0.6158 & 0.6000 & 0.5347 & 0.5405 \\
\hline 16. & 0.9178 & 0.7684 & 0.6745 & 0.6651 & 0.9230 \\
\hline 17. & 0.8590 & 0.7352 & 0.7711 & 0.6888 & 0.9523 \\
\hline 18. & 1.0000 & 0.9212 & 0.6431 & 0.5000 & 0.5000 \\
\hline
\end{tabular}

The Grey relational coefficients are calculated to express the relationship between the ideal $($ best $=1)$ and the actual experimental results. Let $X_{0}$ be reference series

$$
X_{0}=\left\{X_{0}(1), X_{0}(2) \ldots X_{0}(n)\right\}
$$

And $X_{i}$ the compared series

$$
X_{i}=\left\{X_{i}(1), X_{i}(2), \ldots ., X_{i}(n)\right\}, \quad i=1,2, \ldots . n .
$$

Assume $\Delta_{0 i}(k)$ is the difference between $X_{0}(k)$ and $X_{i}(k)$

$$
\Delta_{0 i}(k)=\left|X_{0}(k)-X_{i}(k)\right|
$$

and there are

$$
\Delta \max =\max \max \Delta_{0 i}(k) \quad \Delta_{\min }=\min \min \Delta_{0 i}(k)
$$

Thus the grey relation coefficient is calculated as:

$$
\gamma_{0 i}(k)=\frac{\Delta_{\min }+\Delta_{\max }}{\Delta_{0 i}(k)+\Delta_{\max }}
$$

The grey relation coefficient of surface roughness, hardness, metal removal rate, normal force and tangential force are shown in Table IV. 


\subsection{Computing the Grey relational grades}

The relation grade for each comparative series is determined by taking an average of the grey relation coefficient of each individual event. The grey relation grade can be expressed by:

$$
\Gamma_{0 i}=\frac{1}{n} \sum_{k=1}^{n} \gamma\left(x_{0}(k), x_{i}(k)\right)
$$

Where $\mathrm{n}$ is the number of process responses.

Table V: Grey Relation Grade for each experiment.

\begin{tabular}{|c|c|}
\hline SI.No & $\begin{array}{c}\text { Grey Relation } \\
\text { Grade }\end{array}$ \\
\hline 1. & 0.6172 \\
\hline 2. & 0.7781 \\
\hline 3. & 0.8037 \\
\hline 4. & 0.7656 \\
\hline 5. & 0.7936 \\
\hline 6. & 0.6454 \\
\hline 7. & 0.8103 \\
\hline 8. & 0.7001 \\
\hline 9. & 0.7916 \\
\hline 10. & 0.7935 \\
\hline 11. & 0.6141 \\
\hline 12. & 0.6739 \\
\hline 13. & 0.6709 \\
\hline 14. & 0.7202 \\
\hline 15. & 0.5871 \\
\hline 16. & 0.7898 \\
\hline 17. & 0.8013 \\
\hline 18. & 0.7129 \\
\hline
\end{tabular}

Table VI: Response table for the grey relational grade.

\begin{tabular}{|c|c|c|c|c|}
\hline \multirow{2}{*}{ SI.No } & \multirow{2}{*}{ Process Parameter } & \multicolumn{3}{|c|}{ Grey relational grade } \\
\cline { 3 - 5 } & No of Pass & Mean I & Mean II & Mean III \\
\hline 1. & 0.7339 & 0.7305 & 0.7137 \\
\hline 2. & $\begin{array}{c}\text { Work Speed }(\mathrm{Vw}) \\
(\mathrm{mm} / \mathrm{min})\end{array}$ & 0.7134 & 0.6971 & 0.7677 \\
\hline 3. & Depth of Cut D $(\mu \mathrm{m})$ & 0.7412 & 0.7346 & 0.7024 \\
\hline 4. & Voltage $(\mathrm{V})$ & 0.7351 & 0.7023 & 0.7421 \\
\hline 5. & Current Duty Ratio $(\%)$ & 0.6866 & 0.7157 & 0.7757 \\
\hline \multicolumn{3}{|c|}{ Total mean value of the grey relational grade $=0.7261$} \\
\hline
\end{tabular}

The results of the Grey relational grade are tabulated in Table V. The mean of the Grey relational grade for each level of the machining parameter can be calculated by taking an average of the Grey relational grade. In additional, the total mean of the grey relational grade for the eighteen experiments is also calculated and shown in Table VI. 


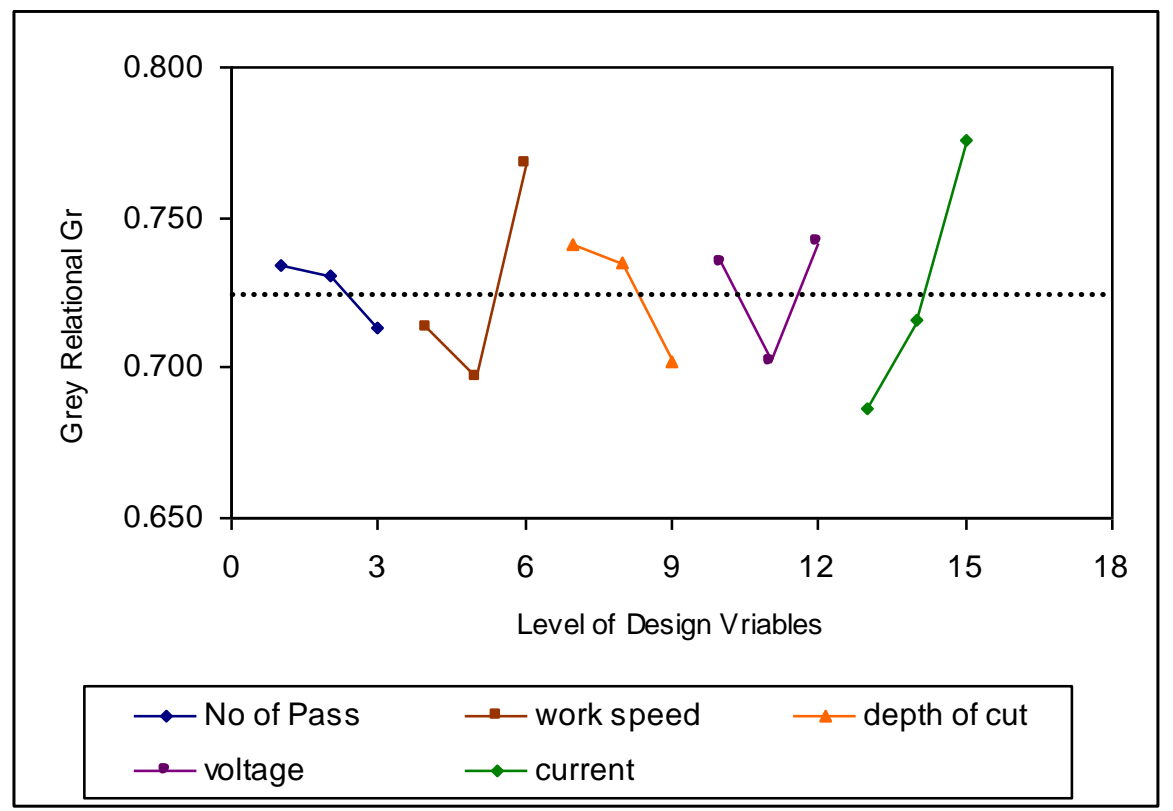

Figure 3: Grey relational grade graph.

Figure 3 shows the grey relational grade graph, in which the dotted line is the value of the total mean of the grey relational grade. Basically, higher the grey relational grade, better are the multiple performance characteristics. However, the relative importance among the grinding process parameters for the multiple performance characteristics still needs to be known in order to determine more accurately, the optimal combinations of the grinding process parameter levels. The optimal grinding process parameters are no of pass at level 1 , work speed at level 3 , depth of cut at level 1 , voltage at level 3 and current duty ratio at level 3.

\subsection{Analysis of variance}

The purpose of the ANOVA is to investigate as to which of the grinding process parameters significantly affects the performance characteristics. This is accomplished by separating the total variability of the grey relational grades, which is measured by the sum of the squared deviations from the total mean of the grey relational grade, into contributions by each grinding process parameter and the error. In addition, the F-test named after Fisher [15] can also be used to determine which of the grinding process parameters have a significant effect on the performance characteristic.

Table VII: Results of ANOVA.

\begin{tabular}{|c|c|c|c|c|c|}
\hline Process parameter & $\begin{array}{c}\text { Degrees of } \\
\text { freedom }\end{array}$ & $\begin{array}{c}\text { Sum of } \\
\text { squares }\end{array}$ & $\begin{array}{c}\text { Mean } \\
\text { squares }\end{array}$ & F- Test & $\begin{array}{c}\text { Contribution } \\
\text { percentage }\end{array}$ \\
\hline No of Pass & 2 & 0.0014 & 0.0007 & 0.0214 & 1.449 \\
\hline $\begin{array}{c}\text { Work Speed }(\mathrm{Vw}) \\
(\mathrm{mm} / \mathrm{min})\end{array}$ & 2 & 0.0163 & 0.0081 & 0.2484 & 16.808 \\
\hline Depth of Cut D( $\mu \mathrm{m})$ & 2 & 0.0051 & 0.0025 & 0.0783 & 5.301 \\
\hline Voltage $(\mathrm{V})$ & 2 & 0.0167 & 0.0083 & 0.2541 & 17.189 \\
\hline Current Duty Ratio $(\%)$ & 2 & 0.0247 & 0.0123 & 0.3759 & 25.431 \\
\hline Error & 7 & 0.0329 & & & 33.819 \\
\hline Total & 17 & & & & 100 \\
\hline
\end{tabular}


Table VII shows the results of ANOVA, which indicate that current duty ratio, voltage and work speed are the significant parameters for affecting the multi response characteristics. The current duty ratio influence is higher of $25.43 \%$ when compared with other parameters. The effect of no of pass and depth of cut are negligible.

\subsection{Confirmation test}

The estimated Grey relational grade $\alpha$ using the optimal level of the machining parameters can be calculated as:

$$
\widehat{\alpha}=\alpha_{m}+\sum_{i=1}^{q}\left(\bar{\alpha}_{i}-\alpha_{m}\right)
$$

where $\alpha_{m}$ is the total mean of the Grey relational grade, $\bar{\alpha}_{i}$ is the mean of the Grey relational grade at the optimal level and $q$ is the number of the machining parameters that significantly affect the multiple response characteristics.

Based on equation 6 the estimated Grey relational grade using the optimal machining parameters can be found. Table VIII shows the predicted and experimental data which shows an improvement in Grey relational grade of 0.8174 .

Table VIII: Results of response performances indicating the initial and optimal settings.

\begin{tabular}{|l|l|l|l|}
\hline & $\begin{array}{l}\text { Initial Machining } \\
\text { Parameter }\end{array}$ & \multicolumn{2}{|c|}{ Optimal Machining Parameter } \\
\cline { 3 - 4 } & $\mathrm{N}_{1} \mathrm{~W}_{1} \mathrm{D}_{1} \mathrm{~V}_{1} \mathrm{C}_{1}$ & $\mathrm{~N}_{2} \mathrm{~W}_{3} \mathrm{D}_{1} \mathrm{~V}_{3} \mathrm{C}_{3}$ & $\mathrm{~N}_{2} \mathrm{~W}_{3} \mathrm{D}_{1} \mathrm{~V}_{3} \mathrm{C}_{3}$ \\
\hline Setting Level & 1.965 & & 1.36 \\
\hline Roughness $(\mu \mathrm{m})$ & 120.33 & & 133.22 \\
\hline Hardness & 2.786 & 3.73 \\
\hline $\begin{array}{l}\text { Metal Removal Rate } \\
\text { (g/min) }\end{array}$ & 6.96 & 5.15 \\
\hline Normal Force $(\mathrm{N})$ & 0.99 & 0.76 \\
\hline Tangential Force $(\mathrm{N})$ & 0.6168 & 0.8174 \\
\hline $\begin{array}{l}\text { Grey Relational } \\
\text { Grade }\end{array}$ & 0.7514 & \\
\hline \multicolumn{3}{|l|}{ Improvement in grey relational grade $=0.2006$} \\
\hline
\end{tabular}

\section{CONCLUSION}

Orthogonal array with Grey relational analysis was employed to optimize the multi response characteristics of ELID grinding process of $\mathrm{Al}-10 \% \mathrm{SiCP}$ composites. The experimental result of the optimal setting shows that there is considerable improvement in the process such as surface roughness, metal removal rate and hardness. The application of this technique converts the complicated multi response process into a single response Grey relational grade and, therefore, simplifies the optimization procedure.

\section{REFERENCES}

[1] Anand Ronald, B.; Vijayaraghavan, L.; Krishnamurthy, R. (2009). Studies on the influence of grinding wheel bond material on the grindability of metal matrix composites, Materials and Design, Vol.30, 679-686

[2] Aguiar, P.R.; Dotto, F.R.L.; Bianchi, E.C. (2005).Study of Thresholds to Burning in Surface Grinding Process, Journal of the Brazil Society of Mechanical Science \& Engineering, Vol. 27, No.2, 150-156 
[3] Bandyopadhyay, B.P.; Ohmori, H.; Takahashi,I. (1997). Efficient and Stable Grinding of Ceramics by Electrolytic In-Process Dressing (ELID), Journal of Material Processing Technology, Vol. 66, 18-24

[4] Ohmori, H.; Nakagawa, T. (1990). Mirror Surface Grinding of Silicon Wafers with Electrolytic In-Process Dressing. Annals CIRP, Vol. 39, No.1, 329-332,

[5] Ohmori, H.; Takahashi, H.; Bandyopadhyya, B.P. (1996). Highly Efficient Grinding of Ceramic Parts by Electrolytic In-Process Dressing (ELID) Grinding, Materials Manufacturing Process, Vol.11, No.1, 31-44

[6] Spanu, C.; Marinescu, I. (2002). Effectiveness of ELID Grinding and Polishing. International Manufacturing Conference, IMTS, IL, Chicago

[7] Bandyopadhyay, B.P.; Ohmori, H. (1999). The effect of ELID grinding on the flexural strength of silicon nitride, International Journal of Machine Tools Manufacturing, Vol. 39, 839-853

[8] Konig, W.; Wemhoner, J. (1989). Optimizing Grinding of SiSiC, Ceramic Bulletin, Vol. 68, No.3, 545-548

[9] Nian,C.Y.; Yang, W.H.; Tarng, Y.S. (1999). Optimization of Turning Operations with Multiple Performance Characteristics, Journal of Material Processing Technology, Vol. 95, 90-96

[10] Deng, J. (1982). Control problems of grey systems, Systems Control Letter, Vol. 5, 288-294

[11] Deng, J. (1989). Introduction to grey theory, Journal of Grey Systems, Vol.1, No.1, 1-24

[12] Lin, J.L.; Tarng, Y.S. (1998). Optimization of the multi-response process by the Taguchi method with grey relational analysis, Journal of Grey System, Vol.4, No. 4, 355-370

[13] Park, S.H. (1996). Robust Design and Analysis for Quality Engineering, Chapman \& Hall, London

[14] Li,Y.X.; Yang, J.G.; Gelvis, T.; Li, Y.Y. (2008). Optimization of measuring points for machine tool thermal error based on grey system theory, International Journal of Advanced Manufacturing Technology, Vol.35, 745-750

[15] Fisher, R.A. (1925). Statistical Methods for Research Workers, Oliver \& Boyd, London.2 